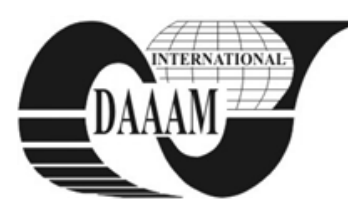

Annals of DAAAM for 2011 \& Proceedings of the 22nd International DAAAM Symposium, Volume 22, No. 1, ISSN 1726-9679 ISBN 978-3-901509-83-4, Editor B. Katalinic, Published by DAAAM International, Vienna, Austria, EU, 2011 Make Harmony between Technology and Nature, and Your Mind will Fly Free as a Bird Annals \& Proceedings of DAAAM International 2011

\title{
FACTORS AFFECTING THE RESERVE DEPLETION LEVEL
}

\author{
BULEARCA, M[arius]; SERBAN, C[laudia] E[lena]; MUSCALU, M[ihai] - S[abin]; \\ VASILE, C[ristina] M[ioara] \& POPESCU, C[atalin]
}

\begin{abstract}
This paper deals with revealing the many factors that affect production and price trend in mining industry, the most important being fluctuations in profit rates, fluctuations in extraction cost and taxes introduced by the Government. Some, such as taxation and the profit, can be treated as variable pricing policy by the government to influence the extraction of non-renewable mineral resources.

Key words: basic economic principle, deposit depletion time, non-renewable mineral resources, price trend, taxation and profit
\end{abstract}

\section{INTRODUCTION}

There are many factors that affect the price-production trend in the mining industry, the most important being: fluctuations in profit rates; fluctuations in extraction cost; taxes introduced by the Government. Some, such as taxation and the profit, can be treated as variable pricing policy introduced by the government to influence the extraction of non-renewable mineral resources.

At the same time, profit level fluctuations may have strong effects on production and price trend in mining industry. At the same time, the charging system may have strong effects on the policies used in the mining industry. Operating with the basic economic principle is restricted by many real world constraints.

Until now, economic analysis in general, and especially that related to the natural resources market, has been characterized by the concept of natural resource scarcity, much of the methodological concepts being closely related to resources allocation problems at micro and macro-economic level. In this sense, natural resources (raw materials and energy) are scarce, according to, on one hand, the growing supply-demand ratio on the market, and on the other hand, the manner in which these resources are found in the production process.

\section{CHANGES IN PROFIT RATE}

Profit level fluctuations may have strong effects on production and price trend in mining industry. First suppose that the profit market rate increases. This means that the revenue rate obtained from an alternative investment project, say term cash deposits, increases. If owners do not undertake any changes of the originally conceived plan, the reserves stock will lead to achieving sub-optimal rates of income over time.

The way to avoid these losses is to move production today. This means that the owners will extract and sell more now, which will lead to lower the price asked on the market. Therefore, less to extract, higher the net price of the remaining reserves may rise. This means that reserves would be exhausted in less time than it would increase profits (Samuelson \& Nordhaus, 1992).

Situation in Fig. 1 illustrates this situation. The curve "ab" is the production and price trend before increasing profit. Immediately after the increase, owners should make an adjustment by increasing production, and then prices start to fall at moment $\mathrm{t}(0)$ to the "a" level.

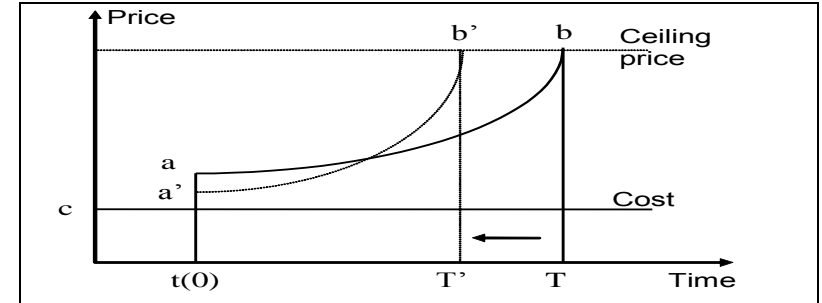

Fig. 1. Effect of profit rate growth on production and price trend, and on deposits depletion time

For the remaining time left the owners will extract less so that the annuity/rent of the reserves left would grow at a higher rate. It will short depletion time from " $\mathrm{T}$ " to " $\mathrm{T}$ "'. The new production and price trend "a'b" will be steeper than the previous one "ab".

If the profit rate falls, opposite phenomenon will occur. Original price will increase as owners push their production into the future by reducing current extraction (Kula, 1994). This is because lowering profit rates make stocks return more attractive than current production. This is obvious also in that a lower profit rate would show a lower growth trend than in the previous case. This means that depletion time increases, as shown in Fig. 2.

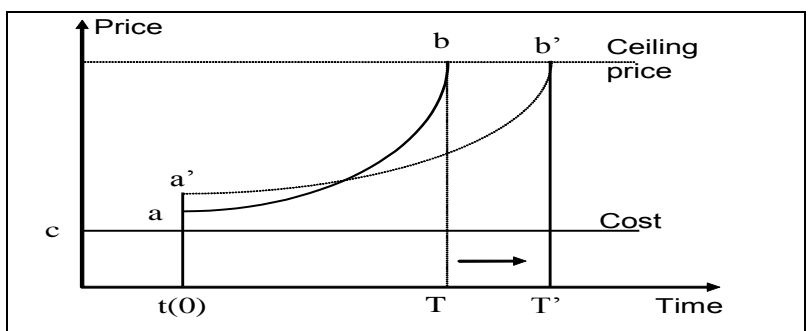

Fig. 2. Effect of profit rate falling on production and price trend, and on deposits depletion time

\section{FLUCTUATIONS IN EXTRACTION COST}

In the beginning let's assume that extraction cost increased. This can happen for a variety of reasons such as lack of skilled labor, wage growth in mining industry and basic resources decline as owners start extraction from fields with difficult access.

An increase in mining costs will reduce the current production level and therefore will increase the starting price, but will reduce further prices. This situation, in turn, will reduce the amount required in the near future and will increase the future quantity (Tietenberg, 1992). The net effect will be the increased depletion time.

The situation is shown in Fig. 3. As the cost of extraction increases, the rent will be reduced. In response, the owners will reduce the current production and will increase, at moment $\mathrm{t}(0)$, the initial price "a" to the new price "a", so the new production and price trend will be "a'b"'. 


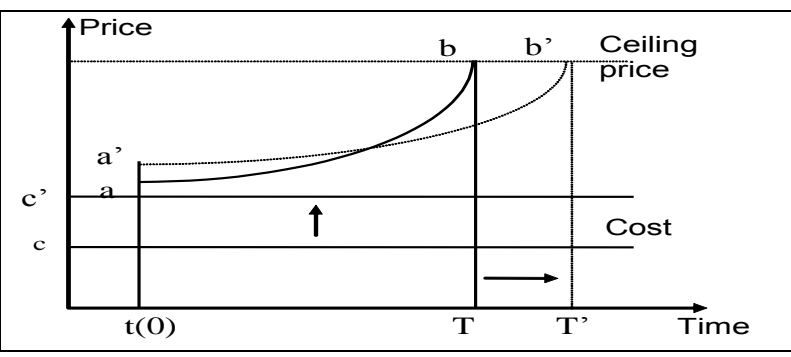

Fig. 3. Effect of extraction cost on production and price trend, and on deposits depletion time

On the other hand, a decrease in the extraction cost will have the opposite effect, by increasing the initial value of the rent. If no adjustment is made, it could lead to a situation in which the cancellation price would be reached faster than desired, leaving owners with unsold stocks.

To avoid such a situation, the owners should lower the starting price. The gain will be that when extraction costs fall, the immediate production level increase, which in turn will reduce the initial price and depletion time (as seen in Fig. 4).

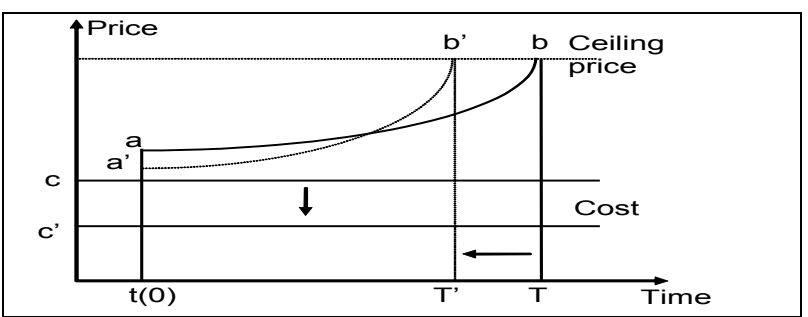

Fig. 4. Effect of extraction cost lowering on production and price trend, and on deposits depletion time

\section{OTHER ECONOMIC CONSIDERATIONS}

Operating with the basic economic principle is restricted by many real world constraints. For example, fluctuations in profit market rates; if it will increase, ceteris paribus, the extraction will increase, and conversely, if rates fall, then there will be a slowdown of mining extraction rhythm.

It is well known that the profit market rate may increase or decrease quite rapidly in a short time. In this case, do we expect an automatic adjustment of the output whenever the profit rate changes?

Therefore it might seem quite unrealistic to expect automatic responses to profit rate changes from resource owners. Supposed the profit market rate increased sufficiently thus constraining owners to increase the extraction so that the accrued money would be invested in deposits with high interest.

Normally, an increase of income production in mining, petroleum and natural gas extractive industries requires an expansion of production capacity, which takes more time. Moreover, the period with high profit rates may not be so long, leading resource owners to think twice before engaging in a costly action to extend the production capacity.

A similar problem may occur in connection with the tax system. Fiscal policies at national level in many countries change with the change in government leadership. Therefore, resource owners cannot be sure on the time length of a particular fiscal policy.

If production capacity and production levels in the extractive industries are based strictly on current tax law, when it suddenly changes, the resource owners may remain with excess capacity or inadequate structures with which they must operate in an optimal way.

Another important factor is the technological change related to natural resources. A change in technology can reduce dependency and hence the demand for a particular resource. For example, let's compare solar energy to fossil fuels. A rapid technological development of solar energy capture can result in substantial demand decrease for fossil fuels.

This type of uncertainty is always in the attention of resource owners when they set their depletion plan for their deposits. Besides the fundamental economic principle, resource owners are guided also by the rule which says: "Sell reserve stocks at the moment when the demand exists for them." When depletion time (" $T$ " in our analysis) is high, it is necessary to develop a technological breakthrough.

Last but not least important issue is the time factor - that is impatience - which can exert a strong influence on depletion time for natural resources deposits. For various reasons, a resource owner can be crazy after money in cash, which may be obtained either by selling its property rights over resources, or by speeding up the extraction regardless the fundamental economic principle rules.

When fields are owned by the state, selling property rights may not be politically possible in most cases, and government remains with only one alternative: fast depletion obtaining immediate cash resources. What happens quite often nowadays.

\section{CONCLUSIONS}

Economic analysis of extractive industry is fundamentally different from the analysis of agriculture, manufacturing and services. The main reason is that the mineral resources are exhaustible resources. In other words, in mining industry an initial stock of reserves will exhaust in time.

Consequently, natural resources appear to be scarce because, as inputs required for production processes, they are not available without limit during the production process. Taking into account given restrictions on the temporal scarce character of certain resources, the theory of optimum allocation of resources is a combination of production factors in such a way to achieve maximum effect.

On the other hand, the economic fundamental principle shows very clearly that, ceteris paribus, the price of mined ore and fossil fuel should increase linearly with the market rate of return. This raises the question whether or not a contradiction between the economic theory of natural resources and the situation observed in the real world is manifested.

\section{REFERENCES}

Barnett, H. (1979). Scarcity and growth revisited, In: Scarcity and Growth Reconsidered (editor: V. K. Smith), Johns Hopkins University Press, ISBN 978-960-474-253-0, Baltimore, MD

Hartwick, J.M. \& Olewiler, N.D. (1986). The Economics of Natural Resource Use, Harper \& Row, ISBN 0060426950, New York

Home, C.N. (1979). Natural Resources Economics, Issues, Analysis and Policy, Wiley, ISBN 978-960-474-253-0, New York

Kula, E., (1994). Economies of Natural Resources, the Environment and Policies, Second Edition, Chapman and Hall, ISBN 0-412-57640-6, London

Pearce, D.W. (1983). Cost-benefit Analysis, Second Edition, MacMillan, ISBN 0333120639, London.

Pearce, D.W. \& Turner, R.K. (1990). Economics of Natural Resources and the Environment, Harvester Wheatsheaf, ISBN 074500225 0, London

Samuelson, P.A. \& Nordhaus, W.D. (1992). Economics, 14-th Edition, McGraw Hill Book Co., ISBN 0-07-1180648, New York

Tietenberg, T. (1992). Environmental and Natural Resources Economics, Third Edition, Harper-Collins, ISBN 0-67346328-1, New York 